\title{
Research of market competitive situation of energy service industry under the perspective of value network
}

\author{
Jun Dong, *Xu Li and Yun $\mathrm{Hu}$ \\ North China Electric Power University \\ Beijing, China \\ dongjun221624@163.com,m13051612801@163.com, \\ 13613831771@163.com
}

\begin{abstract}
Energy service industry is an emerging industry which involved multi-subject, multi-product, multi-technology and multi-value, and is a complicated network system. This paper studies the energy services industry from the perspective of value network, analyzes the value network characteristics of each subject in the industry network, what's more, based on the theory of network, use the dynamic network model to describe the network characteristics of the energy service industry. On this basis, we use Markov prediction analysis method to study the market competition situation of energy service industry based on market forecast and support energy service companies to make market decision.
\end{abstract}

Keywords: Value Network; Energy Service Industry; Market Competitive Situation

\section{Introduction}

As the problem of energy shortage and climatic variation becoming warmer and warmer, Energy conservation becomes one of the important content of sustainable development of human society which concerned by all countries. The international pressure to reduce emissions and the need of sustainable development force the world to find effective ways of energy conservation and emissions reduction. There into, energy performance contracting (EPC) is proved to be an effective way of energy conservation and emissions reduction after recent decades of development, especially after the successful experience of western developed countries. And gradually create an emerging industries form------ energy service industry which taking contract energy management mechanism as commercial model and energy conservation Service Company as representative.

With the development of Internet and information technology, the fierce market competition makes enterprises transform the traditional supply chain to value network to meet the growing demands of customers. As a new theory 
different from the traditional value chain, the value network has the following characteristics: based on the requirement of the customer, highly collaborative, rapid response and low cost.

At present, the understanding of energy service industry network is not very clear. There is not a consummate system. The researches of value generation and transmission mechanism as well as the value network are absent. To study the energy service industry from the perspective of value network and synthetically considering the industrial value advantage in the new social conditions, market conditions, specialized division of labor and the ecological environment. It will contribute to the optimization and Innovation of energy service industry structure and industry development model. It also can be applied to comprehensive energy services and environmental services, etc.

\section{Literature Review}

Energy service industry still belongs to the emerging industry in China, Recent years; research in the field of energy service gains more and more attention.

The macro level: Literature [1] points out the trend of the development of the energy service companies are cancelling subsidies, privatization and internationalization competition. Literature [2] studies the policy background and current situation of the development of the European energy- service industry, putting forward the long-term strategy to promote the development of it. Literature [3] introduces the concept of business model to the energy service industry and points out the main internal and external obstacles which impact the development of energy service industry. Literature [4] combs the research results of energy service industry at home and abroad, pointing out that the existing research is lack of economic theory and effective coordination of energy service clients as well as contractors operating activities are the core issues of industry development. Literature [5] analyzes the factors influencing the core competitiveness of energy service industry and studies the drive to the healthy development of the industrial resources optimization integration model.

The micro level: Literature [6] introduces the theory of the dynamic alliance to energy-saving benefit sharing mechanism, uses fuzzy comprehensive evaluation method to determine the risk coefficient of each participation main body and establishes the benefit sharing model between the ESCO and the customer.

For the research of value network model, Literature [7] points out that the value network emphasizes on innovative. Information becomes the main characters and directly participates in value creation. Literature [8] considers that the enterprise value network has five basic competing advantage effects which are internet economy, economies of scale, risk versus, viscous effect and 
speed effect. About the constitution of the value network, Literature [9] thinks that value network is the objective existence. It consists of utility system, resources selection, rules and regulations, contact information, market pattern and system of value activities and other factors. Literature [10] builds a value network model in view of the service ecosystem under the business environment and makes a simple application.

Study of energy service industry from the perspective of value network at home and abroad is still inadequate. The theoretical system is not perfect. It will help to clear up the energy service industry dynamic network structure and value generation and transmission mechanism if the value network theory being applied to the energy service industry.

\section{The Construction of Energy Service Industry Value Network}

Energy service industry is still an emerging industry in China. The Industrial development is still not perfect. The whole industry chain structure is simple. Both parties are mainly engaged in energy service and energy-using units or enterprises. The product exchanged is energy service. ESCO and energy-using units or enterprises are respectively the energy service suppliers and demanders. In this way, a simple industry chain formed. The upstream suppliers of ESCO mainly include all kinds of energy-saving equipment manufacturing enterprises, energy-saving products production enterprises, energy-saving technology research center and energy investment institutions as well as the construction units, design units, the third party certification bodies, etc. They provide what energy service need, like equipment, technologies, capital, products, etc. And they are the most upstream in the energy service industry chain. Upstream suppliers are not directly involved in the energy service trade. They provide energy-using enterprises or units with energy saving equipment, technology, products and so on just in case that the energy-using enterprises or units do the energy consumption work by themselves. In the case of outsourcing energy service to ESCO, energy-using enterprises or units provides ESCO with energy-saving equipment, technology, capital, products, etc. And provide energy services for energy-using enterprises or units by ESCO. There are three major energy-intensive industries that are industrial enterprises, construction industry and transportation industry in China. Energy-using enterprises can buy energy-saving equipment, product, technology and so on from all kinds of energy-saving equipment manufacturing enterprises, energy-saving products production enterprises, energy-saving technology research center and other suppliers and do the energy- saving reconstruction themselves. The energy-saving service can also be outsourced to ESCO. ESCO will provide a 
full range of energy-saving renovation. In this condition, energy-using enterprise is the demand side. They accept energy services from ESCO.

ESCO, upstream enterprises and downstream enterprises constitute the energy service industry chain together. The value network emphasizes customer demand as the center of it, thus forms the dynamic value network of energy service industry. As shown in Figure1.

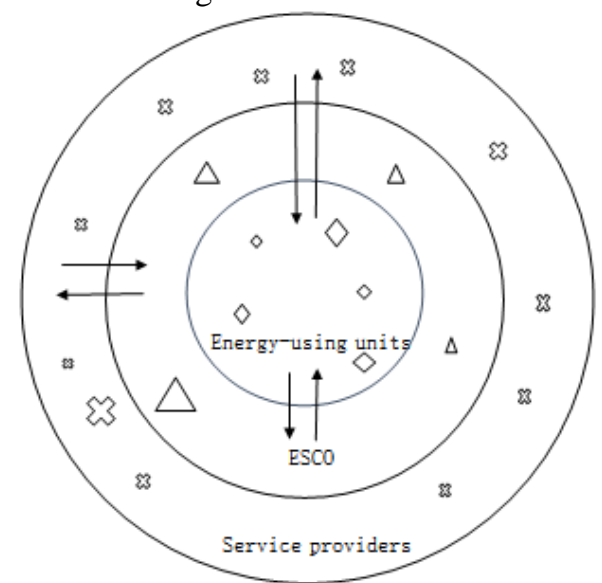

Fig. 1. Dynamic value network of energy service industry

\section{Analysis of ESCO Competition Situation based on Market Forecasting}

With the rapid development of information and network technology, the management environment of enterprises is transforming from relatively stable static environment before to increasingly complex and dynamic environment which is full of uncertainty. Enterprises focus on their strategic value activity only is no longer sufficient now. A single enterprise should attach importance to the competition situation in the value network context; establish contact with the related interest groups through value network to obtain synergies farthest.

Only strengthening the judgment of market changes, taking the competition strategy actively and improving their own competitiveness can make them be in an impregnable position in the market competition. We research on the change of ESCO's market share in energy services industry value network according to the Markov prediction method.

There are three ESCOs (A, B, C) in a place, Energy-using units choose to purchase energy service from which of them directly according to the price, size, service attitude, management level and other factors. The condition changes monthly. Now, according to the change amount of users in August and September, we analyze the amount of users in the following three months. 


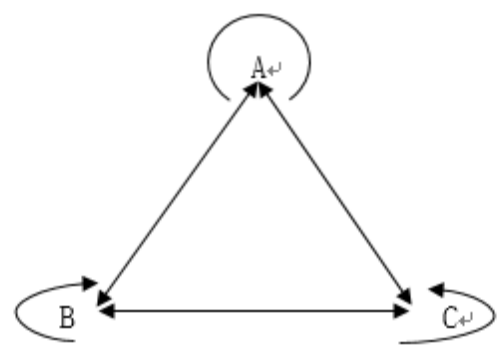

Fig. 2. Competition structure of ESCO

Based on the historical data, we assume that the customer transition between any two ESCOs during month 8-9 is shown in Table 1 below.

Table 1. The amount of customer transition

\begin{tabular}{|c|c|c|c|c|}
\hline ESCO & A & B & C & Aug \\
\hline A & 6 & 4 & 2 & 12 \\
\hline B & 7 & 2 & 3 & 12 \\
\hline C & 9 & 4 & 3 & 16 \\
\hline Sep & 22 & 10 & 8 & 40 \\
\hline
\end{tabular}

In August, the market share of A, B and C is respectively 0.55, 0.25 and 0.2 . The initial state vector is:

$$
S^{(0)}=(0.55,0.25,0.2)
$$

The transfer probability from Aug to Sep is:

$$
P_{11}=\frac{6}{12}=0.50 P_{12}=\frac{4}{12} \approx 0.33 P_{13}=\frac{2}{12} \approx 0.17
$$

In the same way, we can arrive at the transfer probability of B and $\mathrm{C}$. The transition probability matrix is:

$$
P=\left(\begin{array}{lll}
0.50 & 0.33 & 0.17 \\
0.58 & 0.17 & 0.25 \\
0.56 & 0.25 & 0.19
\end{array}\right)
$$

So the market share of Oct is:

$$
S^{(1)}=S^{(0)} \cdot P
$$




$$
\begin{aligned}
& =(0.55,0.25,0.2)\left(\begin{array}{lll}
0.50 & 0.33 & 0.17 \\
0.58 & 0.17 & 0.25 \\
0.56 & 0.25 & 0.19
\end{array}\right) \\
& =(0.532,0.274,0.194)
\end{aligned}
$$

We can see that the market share of $\mathrm{A}$ and $\mathrm{C}$ will decrease in October, so they should analyze why it would happen and try to make changes. In the same way, we can arrive at the market share of the next two month.

We use the Markov prediction analysis method to predict and analyze the competition situation of energy service companies in the value network. It can judge the future market trend according to the historical data of the enterprise, which helps enterprises to carry out market decisions. Of course, the scope we restrict is limited. Energy service companies are faced with lots of value subjects within the industry. Scale economy of the value network, risk antagonism, viscous effect, speed effect and many other factors have impact on value generation and transfer trajectory. These aspects ask we to do further research needed.

\section{Summary}

As can be seen from the energy services industry value network, energy service industry is a large, complex and multiple interests involved system in which value dynamically flows. Studying the energy service industry from the perspective of value network, synthetically considering the industry value advantage of energy service required by the new social conditions, market conditions, the professional division of labor and the ecological environment will be helpful to the optimization of energy service industry structure and industry development mode innovation. And it can also be applied to comprehensive energy services and environmental services, etc. Energy service industry developing rapidly and the market mechanism is continually improved. However, most of the energy service companies are limited by capital, technology as well as the development of the personnel. Besides, the customer acceptance for the energy service remains to be improved. Energy service companies must grasp the market opportunities, forecast the market competition situation, grasp the competitive elements, improve competition ability, and expand market share.

\section{Reference}

1. Edward Vine. An international survey of the energy service company 
(ESCO) industry [J]. Energy Policy, 2005, (33): 691-704.

2. Paolo Bertoldia, Silvia Rezessyb, Edward Vinec. Energy service companies in European countries: Current status and a strategy to foster their development [J]. Energy Policy, 2006, (34): 1818-1832.

3. Satu Patari, Kirsi Sink konen. Energy Service Companies and Energy Performance Contracting: is there a need to renew the business model? Insights from a Delphi study [J]. Journal of Cleaner Production, 2013: 1-8.

4. Huang Jiatao, Zhang Depeng, Lin Hong ling, research overview of energy-saving service industry[J], Journal of Management, 2012, 25(3):73-76(In Chinese)

5. Wang Jingmin, Sun Yanfu, Kang Jun jie. Research on the driver model which promotes the core competitiveness of energy-saving service industry [J]. Resources and Industry, 2011,13(3): 151-154.(In Chinese)

6. Zhao Dan. The research of economic benefits of energy-saving projects evaluation and sharing mechanism [D].North China Electric Power Universiy (Hebei), 2008.(In Chinese)

7. Zhang Huimin, Jiao Zheng ming, Li Yun feng. Research overview of Value network theory [J].China's e-commerce, 2011(7):305-306.(In Chinese)

8. Zhou Xuan. Research on the competitive advantage of the enterprise value network [J].Chinese Industrial Economy, 2005(5):112-118.(In Chinese)

9. Liu Desheng. The competitive advantage of multinational companies in perspective of value network.[J].Foreign Economic and Trade, 2007(2): 57-58.(In Chinese)

10. Li F, Tian C, Cao R Z, et al. Value network model for service ecosystem in business environment[C]// Network Operations and Management Symposium, 2008. NOMS 2008. IEEE. IEEE, 2008:955-958.(In Chinese) 